\title{
Acute Intermittent Porphyria: A Reversible Cause of Cachexia
}

\section{Bernardino Roca* and Manuel Roca}

Medicine Department, Hospital General, University Jaume I, Castellon, Spain

\begin{abstract}
Acute Intermittent Porphyria (AIP), the most common of acute porphyrias, is due to deficient activity of the enzyme porphobilinogen deaminase. Clinically presents with acute attacks, which comprise a variety of neuropsychiatric and visceral symptoms. The attacks may be precipitated by drugs, alcohol, smoking, reduced caloric intake, infection, surgery, psychological stress, or hormonal changes. Diagnosis is based on demonstration of markedly increased levels of precursors of porphyrins in blood or urine and deficient activity of the responsible enzyme in erythrocytes. Treatment consists of administering glucose and intravenous heme derivatives, and avoidance of precipitating factors. We report a patient with AIP, who presented with severe and protracted symptoms that led her to an impressive state of cachexia.
\end{abstract}

Keywords: Acute intermittent porphyria; Porphobilinogen deaminase; Cachexi

\section{Introduction}

The porphyrias are a group of disorders of the heme biosynthesis pathway that generally present in the adult age with neurologic, visceral or cutaneous symptoms. They occur as a result of the toxic effects of porphyrins and their precursors, which are produced in excess amounts due to lack or deficiency of enzymes.

There are at least two ways to classify the different types of porphyrias. Historically, depending on the primary affected site, these disorders have been subdivided into erythropoietic and hepatic. However, from a clinical point of view, it seems most suitable to classify them into acute and non-acute forms, thereby primarily considering if the patient does or does not experience potentially life-threatening acute neurological attacks.

Porphyria cutanea tarda, a hepatic non-acute porphyria, is the most frequent of all types of porphyria, with an approximate prevalence of one case per 10,000. Clinically presents with photosensitivity, skin fragility, crusts, hyperpigmentation, hypertrichosis, and other cutaneous changes [1].

Acute Intermittent Porphyria (AIP), another hepatic porphyria, is the most common acute porphyria. Clinically presents with acute attacks, which comprise a variety of neuropsychiatric symptoms, abdominal pain, constipation, vomiting, urinary retention, muscle weakness, diffuse pain, hypertension, tachycardia, fever, excess sweating, convulsions, sensory loss, and respiratory paralysis that can lead to coma and death. These acute attacks may be precipitated by porphyrinogenic drugs, alcohol ingestion, smoking, reduced caloric intake due to fasting or dieting, infection, surgery, psychological stress, and hormonal changes [2].

We report here on a patient with AIP, with symptoms so severe that lead her to a state of extreme weakness and wasting.

\section{Case Report}

An 18-year-old woman presented with a six-month history of repetitive episodes of intense abdominal pain, nausea, vomiting, constipation, irregular menses, diminished appetite with $10 \mathrm{~kg}$ weight loss, and severe generalized weakness. Her past medical record was unremarkable, except for a smoking habit. She didn't drink alcohol, and she didn't take oral contraceptives or other drugs. The patient was
$1.77 \mathrm{~m}$ tall and weighed $38 \mathrm{~kg}$, with a Body Mass Index (BMI) of 12.1 $\mathrm{kg} / \mathrm{m}^{2}$, axillary temperature was $37.3^{\circ} \mathrm{C}$, her abdomen was diffusely tender, and weakness grade 3 was noted in all her extremities, while the rest of the examination was normal.

Blood analyses showed hemoglobin $10.2 \mathrm{~g} / \mathrm{dl}$ with normal mean corpuscular volume, White Blood Cell count (WBC) 2,800 per $\mathrm{mm}^{3}$ with normal formula, platelets 115,000 per $\mathrm{mm}^{3}$, Alanine Aminotransferase (ALT) $245 \mathrm{U} / \mathrm{L}$, aspartate aminotransferase $192 \mathrm{U} / \mathrm{L}$, gamma glutamyl transpeptidase $55 \mathrm{U} / \mathrm{L}$, lactic dehydrogenase $481 \mathrm{U} / \mathrm{L}$, IgG $2010 \mathrm{mg} /$ $\mathrm{dL}$, total cholesterol $293 \mathrm{mg} / \mathrm{dL}$, iron $39 \mu \mathrm{g} / \mathrm{dL}$, transferrin saturation $11 \%$, ferritin $34 \mathrm{ng} / \mathrm{mL}$, while all other tests, including serum immunoelectrophoresis, thyroid and adrenal hormones, lead, copper, ceruloplasmin and angiotensin-converting enzyme, were normal. Urine routine analysis and immunoelectrophoresis were normal. A lumbar puncture yielded a transparent Cerebrospinal Fluid (CSF) with a WBC count of one mononuclear cell per $\mathrm{mm}^{3}$, glucose $62 \mathrm{mg} / \mathrm{dL}$ and proteins $23 \mathrm{mg} / \mathrm{dL}$; oligoclonal bands were absent, and cytology was negative for malignant cells. Bone marrow aspirate and biopsy revealed hypoplasia of all three cell lines and mild megakaryocytic dysplasia. Cultures of blood, urine, CSF and bone marrow were negative. Serological blood tests for syphilis, toxoplasmosis, brucellosis, salmonellosis, cryptococcosis, leishmaniasis, infectious mononucleosis, rickettsiosis, borreliosis, hepatitis A, hepatitis B, hepatitis C, HIV infection and cytomegalovirus infection were negative. Serological CSF tests for syphilis, brucellosis, cryptococcosis and borreliosis were also negative.

An electromyography revealed nonspecific changes, suggestive of an incipient inflammatory demyelinating polyradiculoneuropathy. All the following tests were normal or showed inconclusive results: chest radiographs, electrocardiogram, echography of the abdomen and pelvis, echocardiogram, upper gastrointestinal endoscopy, barium meal and follow through examination, colonoscopy, and computed

*Corresponding author: Bernardino Roca, Medicine Department, Hospital General, University Jaume I, Catalunya, 33-A, 4-12004, Castellon, Spain, E-mail: brocav@meditex.es

Received July 11, 2012; Accepted August 20, 2012; Published August 22, 2012

Citation: Roca B, Roca M (2012) Acute Intermittent Porphyria: A Reversible Cause of Cachexia. J Clin Case Rep 2:184. doi:10.4172/2165-7920.1000184

Copyright: ( 2012 Roca B, et al. This is an open-access article distributed under the terms of the Creative Commons Attribution License, which permits unrestricted use, distribution, and reproduction in any medium, provided the original author and source are credited. 
tomographies and magnetic resonance images of the head, abdomen and pelvis.

Finally results of porphyrin urine analyses showed total porphyrins $1122 \mu \mathrm{g}$ per day (normal value: < 220), uroporphyrins $598 \mu \mathrm{g}$ per day (normal: < 60), delta-aminolevulinic acid (ALA) $81.7 \mathrm{mg}$ per day (normal: 1-7) and porphobilinogen (PBG) $33 \mathrm{mg}$ per day (normal < 2). Repeated porphyrin urine analyses showed similar results, while stool porphyrins were normal. PBG Deaminase (PBGD) activity in erythrocytes was $56 \mathrm{U} / \mathrm{L}$ (normal: 85-160 U/L). Treatment was instituted with glucose infusion and intravenous human hemin (Orphan Europe), at the dose of $3 \mathrm{mg} / \mathrm{kg}$ once daily for four days, following the recommendations of the manufacturer. Symptoms dramatically improved. Five months later, the patient was in good health and had gained $12 \mathrm{~kg}$ in weight. Blood analyses were normal except for a moderately increased ALT. The enzyme remained mildly elevated for ten more months, but it finally normalized. The family study revealed porphyrin and PBGD activity results similar to those of the patient in the patient's mother, although the mother had never presented symptoms suggestive of porphyri.

\section{Discussion}

AIP is an autosomal dominant hereditary disease, due to deficient activity of the enzyme PBGD, as a result of different mutations of the encoding gene. The enzyme activity is generally about $50 \%$ of normal in affected patients, although similar levels of activity are usually seen in asymptomatic carriers of the mutation. Our report exemplifies that, with the patient's mother clinically unaffected, despite having an enzyme deficiency similar to that of the patient. More atypical is the considerably elevated urine levels of urine ALA and PBG in our patient's mother, as carriers of the enzyme deficiency with no history of symptoms generally have normal urinary excretion of porphyrins and its precursors [3-5].

AIP is an uncommon condition. Prevalence seems to be lower than 10 per 100,000 in most counties, although higher prevalences have been reported in some particular regions, especially of Northern Europe [6]. The disease is more common in women than in men, and almost always presents at or any time after puberty. Clinical manifestations are due to the toxic effects of porphyrins and their precursors, particularly ALA, on the central and peripheral nervous system, and may vary substantially from case to case. Hyponatraemia, generally due to the syndrome of inappropriate antidiuretic hormone secretion or to electrolyte depletion, is common during acute attacks, but it is nonspecific. The urine is often dark red in color, due to the presence of porphobilin, an oxidized derivative of PBG [7]. Diagnosis is based on demonstration of markedly increased levels of ALA and PBG in blood or urine and deficient activity of the responsible enzyme in erythrocytes. And treatment consists of administering glucose and intravenous heme derivatives, and avoidance of precipitating factors [1].

The condition can be disabling and even fatal [8]. Our case was remarkable for the severity of the clinical manifestations, which led the patient to an impressive state of cachexia and prostration, before a diagnosis could be established. Fortunately treatment was effective, and she finally completely recovered.

It is also remarkable that our patient, after recovery, presented an asymptomatic elevation of ALT, which persisted throughout months, although it finally normalized. Chronic, low-grade abnormalities in liver function tests have already been reported in AIP. Moreover, in a recent report a case of AIP is described that presented with a prolonged elevation of ALT [9].

In brief, to avoid the potentially grave consequences of untreated AIP, a prompt diagnosis of the condition is necessary. Due to the varied presentation of the disease, a high index of suspicion by attending clinicians is required.

\section{Acknowledgements}

Support for the preparation of this work has been provided by the Spanish VACH Cohort and the ISCIII-RETIC (RD06/006).

\section{References}

1. Sarkany RP (2008) Making sense of the porphyrias. Photodermatol Photoimmunol Photomed 24: 102-108.

2. Sassa $S$ (2006) Modern diagnosis and management of the porphyrias. $\mathrm{Br} \mathrm{J}$ Haematol 135: 281-292.

3. To-Figueras J, Badenas C, Carrera C, Muñoz C, Milá M, et al. (2006) Genetic and biochemical characterization of 16 acute intermittent porphyria cases with a high prevalence of the R173W mutation. J Inherit Metab Dis 29: 580-585.

4. Anderson KE, Bloomer JR, Bonkovsky HL, Kushner JP, Pierach CA, et al. (2005) Recommendations for the diagnosis and treatment of the acute porphyrias. Ann Intern Med 142: 439-450.

5. Kauppinen R (2005) Porphyrias. Lancet 365: 241-252.

6. Thunell S, Floderus Y, Henrichson A, Harper P (2006) Porphyria in Sweden. Physiol Res 55: S109-118.

7. Poblete-Gutiérrez P, Wiederholt T, Merk HF, Frank J (2006) The porphyrias: clinical presentation, diagnosis and treatment. Eur J Dermatol 16: 230-240.

8. Solinas C, Vajda FJ (2008) Neurological complications of porphyria. J Clin Neurosci 15: 263-268.

9. Raigal Martín MY, Lledó Navarro JL, Raigal Martín JM, Muriel Patino E, Pérez Pérez E, et al. (2008) [Acute intermittent porphyria and chronic transaminase elevation]. Gastroenterol Hepatol 31: 225-228. 